TITLE:

\title{
Mechanism of incorporation of zinc into hydroxyapatite.
}

AUTHOR(S):

Matsunaga, Katsuyuki; Murata, Hidenobu;

Mizoguchi, Teruyasu; Nakahira, Atsushi

CITATION:

Matsunaga, Katsuyuki ...[et al]. Mechanism of incorporation of zinc into hydroxyapatite.. Acta biomaterialia 2010, 6(6): 2289-2293

ISSUE DATE:

2010-06

URL:

http://hdl.handle.net/2433/126720

RIGHT:

(c) 2010 Elsevier B.V.; この論文は出版社版でありません。引用の際には 出版社版をご確認ご利用ください。; This is not the published version. Please cite only the published version. 


\title{
Mechanism of Incorporation of Zinc into Hydroxyapatite
}

\author{
Katsuyuki Matsunaga ${ }^{\text {a,b }}$, Hidenobu Murata ${ }^{\mathrm{a}}$, Teruyasu Mizoguchi ${ }^{\mathrm{c}}$, and Atsushi \\ Nakahira $^{\mathrm{d}, \mathrm{e}}$ \\ ${ }^{a}$ Department of Materials Science \& Engineering, Kyoto University, Kyoto, 606-8501, Japan \\ ${ }^{\mathrm{b}}$ Nanostructures Research Laboratory, Japan Fine Ceramic Center, Nagoya, 456-8587, Japan \\ 'Institute of Engineering Innovation, The University of Tokyo, Tokyo, 116-0013, Japan \\ ${ }^{\mathrm{d}}$ Department of Materials Science, Graduate School of Engineering, Osaka Prefecture \\ University, Osaka, 599-8531, Japan
}

eOsaka Center, Institute of Materials Research (IMR), Tohoku University, Sakai, 599-8531, Japan

*Corresponding author. Tel.:+81-75-753-5454; fax:+81-75-753-5447.

E-mail address: k.matsunaga@materials.mbox.media.kyoto-u.ac.jp (K. Matsunaga)

\begin{abstract}
An atomic-level incorporation mechanism of $\mathrm{Zn}^{2+}$ in hydroxyapatite (HAp), which is a potential dopant for promoted bone formation, was investigated, based on first-principles total energy calculations and experimental x-ray absorption near edge structure (XANES) analyses. It was found that $\mathrm{Zn}^{2+}$-doped HAp tends to have $\mathrm{Ca}$ deficient chemical composition and substitutional $\mathrm{Zn}^{2+}$ ions are associated with a defect complex of a $\mathrm{Ca}^{2+}$ vacancy and two charge-compensating protons. Moreover, first-principles calculations demonstrated that $\mathrm{Zn}^{2+}$ incorporation into HAp can take place through occupying the $\mathrm{Ca}^{2+}$ vacancy of the defect complex. The $\mathrm{Ca}^{2+}$-vacancy complex is not only an origin of calcium deficiency of HAp, but will also play a key role for uptaking trace elements during mineralization.
\end{abstract}

Keywords: first-principles calculation, x-ray absorption spectrum, defect complex, formation energy, solution $\mathrm{pH}$ 


\section{Introduction}

Hard tissues in bones are composed of inorganic calcium phosphate minerals and organic collagen fibrils, and the inorganic minerals play versatile and important roles such as mechanically supporting human bodies and storing or releasing calcium and other ions into body fluids to maintain homeostasis. Although hydroxyapatite $\left(\mathrm{Ca}_{10}\left(\mathrm{PO}_{4}\right)_{6}(\mathrm{OH})_{2}\right.$, HAp) is a representative component of the inorganic part of bone, its chemical composition is generally rather complicated in reality: nonstoichiometric and calcium deficient $(\mathrm{Ca} / \mathrm{P}$ molar ratio $<1.67)$ due to vacancies, foreign cations and anions such as sodium, zinc, magnesium, iron and carbonate $\left(\mathrm{CO}_{3}{ }^{2-}\right)$ ions, which are uptaken from the surrounding body fluids during bone metabolism [1.2]. Foreign ions also control microstructures, crystallinity, and physicochemical properties, such as solubility and osteoconductivity, of HAp minerals. From a viewpoint of osteoporosis prevention, zinc and strontium ions are deliberately doped to promote bone formation and/or to retard bone absorption by their incorporation into HAp minerals [3,4]. Although the trace elements and dopants in HAp minerals will have individual roles in bone formation or bone remodeling processes, little is known about an incorporation mechanism of the foreign ions into HAp minerals and their local physical and chemical environments at an atomic-scale regime, relevant to biological HAp properties.

Among foreign ions commonly involved in HAp, the present study focuses on $\mathrm{Zn}^{2+}$ incorporation into HAp, because $\mathrm{Zn}^{2+}$ is a typical dopant to promote bone formation. ${ }^{3}$ However, there are a number of contradictory data on the $\mathrm{Zn}^{2+}$ incorporation, and the experimental zinc solubility in HAp, previously reported, exhibits a wide variation ranging from a few to $15 \mathrm{~mol} \%$ [5-7]. Even the essential solubility of $\mathrm{Zn}^{2+}$ into HAp is still ambiguous, and thus it is of scientific importance to understand a detailed mechanism of the zinc incorporation. As the mechanism, it can be simply considered that $\mathrm{Zn}^{2+}$ ions substitute for isovalent $\mathrm{Ca}^{2+}$ ions in HAp. However, previous theoretical 
investigations on $\mathrm{Zn}^{2+}$ substitution for Ca exhibited the quite limited solubility of at most $10^{-2}$ mol\%, i.e., energetically unfavorable, which indicates that $\mathrm{Zn}^{2+}$ incorporation is not necessarily explained by the simple substitution mechanism [8]. On the other hand, many of previous experiments showed that $\mathrm{Zn}^{2+}$-doped HAp precipitated from aqueous solutions often contain a certain amount of $\mathrm{Ca}^{2+}$ vacancies, namely the molar ratio of $(\mathrm{Ca}+\mathrm{Zn}) / \mathrm{P}<1.67[6,7,9,10]$. Based on these results, it can be postulated that another mechanism involving $\mathrm{Ca}^{2+}$ vacancies will work in $\mathrm{Zn}^{2+}$ incorporation. Understanding the $\mathrm{Zn}^{2+}$ incorporation mechanism will become a definite step to explore the detailed $\mathrm{Zn}^{2+}$ effect on the promoted bone formation. In order to clarify this issue, therefore, the present study attempts to investigate the thermodynamic stability, the incorporation mechanism and the local chemical environment of $\mathrm{Zn}^{2+}$ in HAp, using first-principles total energy calculations and experimental XANES for model HAp samples. Special attention is paid for a $\mathrm{Ca}^{2+}$-vacancy effect on $\mathrm{Zn}^{2+}$ incorporation.

\section{Methods}

\subsection{Experimental Procedure}

$\mathrm{Zn}^{2+}$-doped HAp samples were also synthesized by precipitation using $0.1 \mathrm{M}$ $\mathrm{Ca}\left(\mathrm{NO}_{3}\right)_{2} \cdot 4 \mathrm{H}_{2} \mathrm{O}$ and $0.1 \mathrm{M}\left(\mathrm{NH}_{4}\right)_{2} \mathrm{HPO}_{4}$ solutions. $0.1 \mathrm{M} \mathrm{Zn}\left(\mathrm{NO}_{3}\right)_{2} \cdot 6 \mathrm{H}_{2} \mathrm{O}$ solution was used as the zinc ion source, and a nominal $\mathrm{Zn} /(\mathrm{Ca}+\mathrm{Zn})$ molar ratio was set at $1 \%$. Such a small amount of $\mathrm{Zn}^{2+}$ is based on the face that zinc is known to basically destabilize the HAp phase and thus more zinc addition may prevent producing single-phase $\mathrm{Zn}^{2+}$-doped HAp. The solutions were mixed so as to produce samples with a stoichiometric $(\mathrm{Ca}+\mathrm{Zn}) / \mathrm{P}$ molar ratio of 1.67 , and were stirred for an hour while the solution $\mathrm{pH}$ is kept at $\mathrm{pH}=10 . \mathrm{NH}_{3}$ solutions were used to adjust $\mathrm{pH}$ values of the solutions. After one-hour maturation, the precipitated HAp powders were washed by 
distilled water and were dried at $323 \mathrm{~K}$ for 24 hours. According to XRD analyses for the present samples, formation of HAp single phase was confirmed and no secondary phase such as tricalcium phosphate (TCP) was observed [11,12]. This fact was also the case after annealing in air at $773 \mathrm{~K}$, and then there was no pronounced difference in XRD and XANES profiles between before and after annealing, which indicates that doped Zn ions are not simply adsorb on HAp surfaces but are indeed incorporated into the HAp lattice. Chemical analyses were performed by inductively coupled plasma atomic emission spectroscopy (ICP-AES). The resultant $(\mathrm{Ca}+\mathrm{Zn}) / \mathrm{P}$ molar ratio was found to be 1.51, which indicates the Ca vacancies of less than $10 \%$ involved in the samples. The molar ratio of the doped sample was still smaller than that of the undoped sample $(\mathrm{Ca} / \mathrm{P}=1.63)$ produced by the same experimental condition. It can be thus speculated that $\mathrm{Zn}$ doping tends to induce more calcium deficiency in HAp. The similar trend of the decreased $(\mathrm{Ca}+\mathrm{Zn}) / \mathrm{P}$ ratio from stoichiometry in $\mathrm{Zn}^{2+}$-doped $\mathrm{HAp}$ was also observed in previous studies [6,7].

For the $\mathrm{Zn}^{2+}$-doped HAp samples thus obtained, Zn-K XANES was measured at the SPring-8 (Hyogo, Japan) [13]. The XANES data were collected with the fluorescent mode using the highly-sensitive 19-elements Ge solid states detector and the Si (311) double crystals to monochromate incident X-ray beams. It is well known that XANES generally reflects local atomic coordination and chemical bonding state for an atom of interest, and it is suitable, therefore, to analyze detailed chemical environment of $\mathrm{Zn}^{2+}$ dissolving into HAp.

\subsection{Computational Procedure}

For theoretical analyses on thermodynamic stability of $\mathrm{Zn}^{2+}$ in $\mathrm{HAp}$, first-principles band-structure calculations were performed based on the projector 
augmented method, implemented in VASP [14,15]. The generalized gradient approximation (GGA) proposed by Perdew et al. was used for the exchange-correlation potential [16]. Wave functions were expanded by plane waves up to a cutoff energy of $500 \mathrm{eV}$, and atoms were allowed to relax until forces on atoms converged to less than $0.05 \mathrm{eV} / \AA$. Brillouin zone sampling was done at the $\Gamma$ point for the HAp supercells described below. These computational conditions ensure a good computational accuracy of less than 1.0 meV/atom. At the beginning, HAp supercells containing 352 atoms were generated by doubling the hexagonal unit cell (space group $P 6_{3} / m$ ) in three dimensions, and were used for the present defect calculations [2,17]. Using such a large supercell assumes the calculations in the dilute limit, which is advantageous to investigate essential dopant solubility in systems with relatively low concentrations.

In order to study the $\mathrm{Zn}^{2+}$ substitution in Ca-deficient HAp, a $\mathrm{Ca}^{2+}$ vacancy at Ca-2 (triangular $\mathrm{Ca}$ site about the $\mathrm{OH}^{-}$arrangement along the $c$ axis) charge-compensating two protons (see Fig. 1(a)) was introduced into the supercell. This vacancy-proton defect complex (charge neutral) can be represented by $\left(\mathrm{V}_{\mathrm{Ca}}-2 \mathrm{H}_{\mathrm{i}}\right)^{\times}$, according to the Kröger-Vink notation, and was theoretically found to be the energetically most stable defect in HAp $[18,19]$. Experimentally, the inclusion of lattice water $[7,20]$ and the preferential loss of Ca-2 [21] were also pointed out, which also suggests that the Ca-vacancy defect complex is a plausible defect model in Ca-deficient HAp. The perfect and Ca-deficient HAp supercells were used for calculations of $\mathrm{Zn}^{2+}$ incorporation in HAp.

Based on total energies of HAp supercells $\left(E_{\mathrm{T}}\right)$, defect formation energies $\left(\Delta H_{\mathrm{f}}\right)$ were evaluated. If a $\mathrm{Zn}^{2+}$ is introduced into HAp in some form of a neutral charge state, $\Delta H_{\mathrm{f}}$ can be written as $\Delta H_{\mathrm{f}}=E_{\mathrm{T}}^{\mathrm{Zn}}-E_{\mathrm{T}}^{0}+\sum_{\mathrm{i}} n_{\mathrm{i}} \mu_{\mathrm{i}}$. Here $E_{\mathrm{T}}^{\mathrm{Zn}}$ and $E_{\mathrm{T}}^{0}$ indicate total energies for $\mathrm{Zn}^{2+}$-doped and undoped supercells, respectively. $\mu_{\mathrm{i}}$ is a chemical potential for an ionic species and $n_{\mathrm{i}}$ is an integer corresponding to the numbers of the 
ionic species to be removed from or added to the undoped supercell. In order to obtain $\Delta H_{\mathrm{f}}$ for $\mathrm{Zn}^{2+}$ in HAp, the chemical equilibrium of HAp with an aqueous solution saturated with respect to HAp and containing a particular concentration of $\mathrm{Zn}^{2+}\left(\left[\mathrm{Zn}^{2+}\right]\right)$ was assumed. In the present case, $\left[\mathrm{Zn}^{2+}\right]$ was set at $1.0 \times 10^{-3} \mathrm{~mol} / \mathrm{L}$, as found in previous solution-precipitation experiments. Ionic chemical potentials for respective ionic species were determined from total energies of pure substances, experimental standard ionic formation energies in solution, and the ionic concentrations in the saturated solution $[8,22]$. Since the ionic concentrations depend on solution $\mathrm{pH}$, the ionic chemical potentials and subsequent defect formation energies also show the $\mathrm{pH}$ dependence. More detailed descriptions for evaluation of the ionic chemical potentials and defect formation energies can be found elsewhere [8,22].

Furthermore, theoretical Zn-K XANES spectra for $\mathrm{Zn}^{2+}$-doped HAp were calculated by two kinds of first-principles methods within the GGA, the plane wave based pseudopotential method in the CASTEP code $[23,24]$ and the full-potential augmented plane wave plus local orbital (APW+lo) method in the WIEN2k code [25]. The CASTEP calculations basically use ultrasoft pseudopotentials. In order to take account of a core-hole effect in electronic excitation, ultrasoft pseudopotentials designed for excited atoms with a core hole are employed in the CASTEP calculations. In the present case, the excited pseudopotential for $\mathrm{Zn}$ was adopted for an excited $\mathrm{Zn}$ atom involved in a HAp supercell. 88-atom HAp supercells (generated by doubling the hexagonal HAp unit cell along the $c$ axis) were used for the spectrum calculations. A plane-wave cut off energy was set to be $400 \mathrm{eV}$, and Brillouin zone sampling was performed by the $2 \times 2 \times 1$ Monkhorst-Pack mesh [26]. In order to make comparison with experiment, photoabsorption cross section (PACS) from matrix elements of electric dipole transition between the core orbital (1s) of $\mathrm{Zn}$ and unoccupied ones was calculated. The PACS thus calculated was broadened by a Gaussian function with full widths at half maximum (FWHM) of $0.5 \mathrm{eV}$ and $1.67 \mathrm{eV}$, to obtain theoretical spectra. The 
theoretical transition energy was also calculated by the pseudopotential calculation of the supercell and the all-electron calculation of the isolated atom, as reported elsewhere [27].

On the other hand, in the WIEN2k calculations, the same computational conditions of the supercell size and $k$-point sampling were used. The plane wave cutoff of $R_{\mathrm{MT}} K_{\max }$ (the muffin-tin radius $R_{\mathrm{MT}}$ and the maximum reciprocal space vector $K_{\max }$ ) was fixed at 3.5 Bohr $\mathrm{Ryd}^{1 / 2}$. In this case, in order to include the core-hole effect, one electron was removed from a core orbital of an atom of interest, and was put at the bottom of the conduction band. Spectral profiles were obtained from the product of the radial part of the transition matrix element and the projected partial density of states for the electric-dipole allowed transition of interest. The total energy difference between the initial and the final state was used as the theoretical transition energy.

It is also noted that theoretical transition energies are generally different from experimental ones. In both kinds of the present spectrum calculations, therefore, Zn-K XANES for ZnO was calculated as a reference, and the transition-energy difference between theory and experiment was used for correction of the calculated spectra for $\mathrm{Zn}$ defects in HAp, which corresponds to $-39.7 \mathrm{eV}$ for the pseudopotential method (CASTEP) and -42.7 eV for the APW+lo method (WIEN2k).

\section{Results and Discussion}

In order to investigate a local environment of $\mathrm{Zn}^{2+}$ substituting for $\mathrm{Ca}^{2+}$ in $\mathrm{HAp}$, the experimental Zn-K XANES in comparison with theoretical spectra were displayed in Fig. 2. The almost identical experimental spectrum for the Zn-doped HAp were obtained by Takatsuka et al. and Tang et al. [28,29], and it was also confirmed that the spectral feature for $\mathrm{Zn}$ doped into HAp is different from those for zinc phosphate 
compounds [28]. Moreover, a Zn-K XANES for 5 mol\% $\mathrm{Zn}^{2+}$-doped HAp was measured in this study, but there was no obvious difference from the present case of 1 mol\% $\mathrm{Zn}^{2+}$-doped HAp.

For the XANES calculations, two kinds of situations for substitutional Zn in HAp were considered: (a) an isolated substitution in perfect HAp and (b) substitutions in the presence of the $\mathrm{Ca}^{2+}$-vacancy defect complex (see Fig. 1). In the former situation, substitutions at Ca-1 (columnar Ca atoms) [2] and at Ca-2 sites were considered, although the Ca-2 site substitution was theoretically found to be more stable $[8,22]$.

First of all, there was no unambiguous difference in spectrum features between the theoretical spectra obtained by the two different methods. It can be said that the computed results in this study are essential and are not affected by the difference in theoretical background for the electronic structure calculations. When a comparison between theory and experiment was made, however, the theoretical spectra of the substitution models in 'perfect HAp’ provided obviously different spectral features from the experimental one: for example, the peak splitting between peaks A (9662 eV) and B (9665 eV), and the position of peak C (9674 eV) were not reproduced. Additionally, the prepeak at around $9656 \mathrm{eV}$ was not found for the Ca-1 substitution, while the shoulder-like feature after the peak B in the theoretical spectra did not agree with the experimental one. These discrepancies indicate that $\mathrm{Zn}^{2+}$ incorporation in HAp cannot be understood by a simple substitution for $\mathrm{Ca}$ in the perfect lattice.

In contrast, for the substitution in 'Ca deficient HAp,' two kinds of Ca-2 sites neighbouring the Ca vacancy site, which form the triangle around $\mathrm{H}_{2} \mathrm{O}$ (denoted by the arrows in Fig. 1(a)), were considered. It is noted that the total energies of the two cases were almost the same with each other and thus no site preference was observed within the present computational accuracy. However, it was found that, when $\mathrm{Zn}^{2+}$ substitutes the Ca-2 site shown in Fig. 1(b), the Zn-K XANES shows a quite reasonable agreement 
with the experimental spectrum (see the second spectrum from the top of Figs. 2(a) and (b)). Especially, it is worth mentioning that the position of the peak $\mathrm{C}$ as well as the separation between A and B were well reproduced. Other spectrum features for the model in Ca deficient HAp, such as the presence of the prepeak at $9656 \mathrm{eV}$ (confirmed from the higher resolution spectrum drawn by the smaller FWHM of $0.5 \mathrm{eV}$ ) and the shoulder-like structure after the peak B, were in better agreement with experiment than those for the models in perfect HAp. In this case, Zn was fivefold coordinated to oxygen (the local coordination environment was considerably distorted and thus the bond distance of $\mathrm{Zn}-\mathrm{O}$ ranged from $0.20 \mathrm{~nm}$ to $0.23 \mathrm{~nm}$ ), and one of the oxygen atoms belonged to the adjacent $\mathrm{H}_{2} \mathrm{O}$ group. It is noted that the $\mathrm{Zn}^{2+}$ substitution at another Ca-2 site considered here (see Fig. 1(a)) exhibited a similar XANES feature (not shown here) with the one at Ca-2 in perfect HAp.

More detailed analyses on the theoretical spectra showed that the pre-edge peak (9658 eV) at Ca-2 in perfect HAp mainly originates from the interaction of Ca with $\mathrm{O}$ of an adjacent $\mathrm{OH}$ group, and the reduced intensity of the pre-edge peak for $\mathrm{Zn}$ in defective HAp is attributed to the covalent interaction of $\mathrm{Zn}$ with the $\mathrm{H}_{2} \mathrm{O}$ group, unlike the interaction with an $\mathrm{OH}$ group. In this regard, Miyaji et al. also pointed out the presence of 'lattice $\mathrm{H}_{2} \mathrm{O}$ ' and the Ca deficiency in $\mathrm{Zn}^{2+}$-doped HAp, whose situation well corresponds to the present argument [7]. It is also noted that substitutional $\mathrm{Zn}^{2+}$ and the defect complex have an attractive interaction (the calculated association energy of $0.07 \mathrm{eV}$ ) and energetically favour the associated structure as displayed in Fig. 1(b). The defect association results in stabilizing formation of the $\mathrm{Ca}^{2+}$-vacancy complex as well as substitutional $\mathrm{Zn}^{2+}$. This may also contribute to the increased Ca deficiency of $\mathrm{Zn}^{2+}$-doped HAp, as compared to the undoped system, as found experimentally.

Since the experimental and theoretical XANES results demonstrated the presence of the $\mathrm{Ca}^{2+}$-vacancy complex in the vicinity of substitutional $\mathrm{Zn}^{2+}$, the $\mathrm{Ca}^{2+}$-vacancy 
defect complex may also play a crucial role for $\mathrm{Zn}^{2+}$ incorporation into HAp. Namely, the $\mathrm{Ca}^{2+}$-vacancy complex will act as possible substitutional sites for $\mathrm{Zn}^{2+}$ incorporation. If this is the case, the $\mathrm{Zn}^{2+}$-incorporation reaction can then be written as $\left(\mathrm{V}_{\mathrm{Ca}}-2 \mathrm{H}_{\mathrm{i}}\right)^{\times}(H A p)+\mathrm{Zn}^{2+}(a q) \rightarrow \mathrm{Zn}_{\mathrm{Ca}}(H A p)+2 \mathrm{H}^{+}(a q)$. It should be noted here that two interstitial protons are released from the defect complex into the surrounding solution in the event of $\mathrm{Zn}^{2+}$ substitution at the vacant site, as a result of charge neutrality requirement. It can be seen in Fig. 3 that the formation energy of substitutional $\mathrm{Zn}^{2+}$ via the vacancy-filling mechanism tends to decrease with rising solution $\mathrm{pH}$ and reaches to zero around $\mathrm{pH}=10$. This indicates that the $\mathrm{Zn}^{2+}$ substitution into HAp is thermodynamically stable according to this mechanism and can take place spontaneously in more alkaline conditions. In fact, experimental $\mathrm{Zn}^{2+}$ introduction into HAp in the solution-precipitation method was commonly performed in the alkaline solution conditions of around $\mathrm{pH}=10-11[6,7,10]$. Such a trend was quite different from the simple ion exchange of $\mathrm{Ca}^{2+}$ and $\mathrm{Zn}^{2+}$ between HAp and solution $\left(\mathrm{Ca}_{\mathrm{Ca}}(H A p)+\mathrm{Zn}^{2+}(a q) \rightarrow \mathrm{Zn}_{\mathrm{Ca}}(H A p)+\mathrm{Ca}^{2+}(a q)\right)$. In this case, the formation energy of substitutional $\mathrm{Zn}^{2+}$ was rather high over the entire solution $\mathrm{pH}$ range, even compared to the case via the vacancy-filling mechansim (see Fig. 3), so that the estimated equilibrium concentration of substitutional $\mathrm{Zn}^{2+}$ was in an order of $\mathrm{ppm}$. The concentration was far below the experimental data [6,7], indicating that the $\mathrm{Zn}^{2+}$ incorporation into HAp cannot be realized by the simple ion-exchange like mechanism. This also supports the important role played by the $\mathrm{Ca}^{2+}$-vacancy complex in the $\mathrm{Zn}^{2+}$ incorporation.

\section{Summary and Conclusions}

In summary, the present study showed that $\mathrm{Zn}^{2+}$ incorporation into HAp does not simply take place by ion exchange but the $\mathrm{Ca}^{2+}$-vacancy defect complexes can act as 
plausible atomic sites for substiutional $\mathrm{Zn}^{2+}$ in HAp. Since the $\mathrm{Ca}^{2+}$-vacancy concentration in $\mathrm{Ca}$ deficient HAp commonly obtained through the solution-precipitation method generally ranges within $10 \mathrm{~mol} \%(1.50<\mathrm{Ca} / \mathrm{P}<1.67)$, it is likely that the $\mathrm{Zn}^{2+}$ substitution is also limited to several mol\%, as found in previous experiments. Following the $\mathrm{Ca}^{2+}$-vacancy filling mechanism, substitutional $\mathrm{Zn}^{2+}$ ions may also diffuse through the HAp lattice with the aid of the remaining $\mathrm{Ca}^{2+}$-vacancy complexes, which will promote ion exchange occurring between HAp crystals and the surrounding aqueous solution. Such a vacancy-filling mechanism should be closely related to versatile incorporation of trace elements into HAp, which is a key process of biomineralization, leading to the development for high-performance metal-ion doped HAp.

\section{Acknowledgment}

This work was supported partly by the Elements Science and Technology Project, the Grant-in-Aid for Scientific Research (B) and on Priority Areas "Nano Materials Science for Atomic-scale Modification 474" from the Ministry of Education, Culture, Sports and Technology (MEXT) of Japan, and the Japan Society of the Promotion Science. The authors also acknowledge I. Tanaka for his support of computation. 


\section{References}

[1] Dorozhkin SV. Calcium orthophosphates. J Mater Sci 2007;42:1061-1095.

[2] Elliott JC. Structure and chemistry of the apatites and other calcium orthophosphates. Amsterdam:Elsevier, 1994.

[3] Kawamura H, Ito A, Miyakawa S, Layrolle P, Ojima K, Ichinose N, et al. Stimulatory effect of zinc-releasing calcium phosphate implant on bone formation in rabbit femora. J Biomed Mater Res 2000;50:184-190.

[4] Marie PJ, Ammann P, Boivin G, Rey C. Mechanisms of action and therapeutic potential of strontium in bone. Calcif Tissue Int 2001;69:121-129.

[5] Patel PN. Magnesium calcium hydroxylapatite solid-solutions - Preparation, IR and lattice-constant measurements. J Inorg Nucl Chem 1980;42:1129-1132.

[6] Bigi A, Foresti E, Gandolfi M, Grazzano M, Roveri N. Inhibiting effect of zinc on hydroxylapatite crystallization. J Inorg Biochem 1995;58:49-58.

[7] Miyaji F, Kono Y, Suyama Y. Formation and structure of zinc-substituted calcium hydroxyapatite. Mater Res Bull 2005;40:209-220.

[8] Matsunaga K. First-principles study of substitutional magnesium and zinc in hydroxyapatite and octacalcium phosphate. J Chem Phys 2008;128:245101.

[9] Li J, Li Y, Zhang L, Zuo Y. Composition of calcium deficient Na-containing carbonate hydroxyapatite modified with $\mathrm{Cu}(\mathrm{II})$ and $\mathrm{Zn}(\mathrm{II})$ ions. Applied Surface Science 2008;254:2844-2850.

[10] Fujii E, Ohkubo M, Tsuru K, Hayakawa S, Osaka A, Kawabata K, et al. Selective protein adsorption property and characterization of nano-crystalline zinc-containing hydroxyapatite. Acta Biomater 2006;2:69-74.

[11] Nakahira A, Sakamoto K, Yamaguchi S, Kaneno M, Takeda S, Okazaki M. Novel Synthesis method of hydroxyapatite whiskers by hydrolysis of $\alpha$-tricalcium phosphate in mixtures of $\mathrm{H}_{2} \mathrm{O}$ and organic solvent. $\mathrm{J}$ Am Ceram Soc 1999;82:2029-2032.

[12] Tamai M, Isshiki T, Nishio K, Nakamura M, Nakahira A, Endoh H. A metastable phase in thermal decomposition of Ca-deficient hydroxyapatite. J Mater Sci Mater Med 2003;14:617-622.

[13] The XANES measurements were performed at the BL01B1 in the SPring-8 (Hyogo, Japan) with the approval of the Japan Synchrotron Radiation Research Institute (JASRI) (Proposal No. 2008B1166, 2009A1533).

[14] Kresse G, Furthmüller J. Efficient iterative schemes for ab initio total-energy calculations using a plane-wave basis set. Phys Rev B 1996;54:11169-11186. 
[15] Blöchl PE. Projector augmented-wave method. Phys Rev B 1994;50:17953-17979.

[16] Perdew JP, Burke K, Ernzerhof M. Generalized gradient approximation made simple. Phys Rev Lett 1996;77:3865-3868.

[17] Kay MI, Young RA, Posner AS. Crystal structure of hydroxyapatite. Nature 1964;204:1050-1052.

[18] Matsunaga K. Theoretical investigation of the defect formation mechanism relevant to nonstoichiometry in hydroxyapatite. Phys Rev B 2008;77:104106.

[19] Zahn D, Hochrein O. On the composition and atomic arrangement of calcium-deficient hydroxyapatite: An ab-initio analysis. J Sol Stat Chem 2008;181:1712-1716.

[20] Berry EE. Structure and composition of some calcium-deficient apatites. J Inorg Nucl Chem 1967;29:317-327.

[21] Jeanjean J, McGrellis S, Rouchaud JC, Fedoroff M, Rondeau A, Perocheau S, et al. A crystallographic study of the sorption of cadmium on calcium hydroxyapatites: Incidence of cationic vacancies. J Sol Stat Chem 1996;126:195-201.

[22] Matsunaga K, Inamori H, Murata $\mathrm{H}$. Theoretical trend of ion exchange ability with divalent cations in hydroxyapatite. Phys Rev B 2008;78:094101.

[23] Clark SJ, Segall MD, Pickard CJ, Hasnip PJ, Probert MJ, Refson K, et al. First principles methods using CASTEP. Z Kristallogr 2005;220:567-570.

[24] Gao SP, Pickard CJ, Payne MC, Zhu J, Yuan J. Theory of core-hole effects in 1s core-level spectroscopy of the first-row elements. Phys Rev B 2008;77:115122.

[25] Blaha P, Schwarz K, Madsen G, Kvasicka D, Luitz J. WIEN2k, An augmented plane wave+local orbitals program for calculating crystal properties. Techn. Universitat Wien Austria. 2001. ISBN 3-9501031-1-2. Karlheinz Schwarz.

[26] Monkhorst HJ, Pack JD. Special points for Brillouin-zone integrations. Phys Rev B 1976;13:5188-5192.

[27] Mizoguchi T, Tanaka I, Gao SP, Pickard CJ. First-principles calculation of spectral features, chemical shift and absolute threshold of ELNES and XANES using a plane wave pseudopotential method. J. Phys.:Condens. Matter 2009;21: 104204.

[28] Takatsuka T, Hirano J, Matsumoto H, Honma T. X-ray absorption fine structure analysis of the local environment of zinc in dentine treated with zinc compounds. Eur Oral Sci 2005;113:180-183.

[29] Tang Y, Chappell HF, Dove MT, Reeder RJ, Lee YJ. Zinc incorporation into 
(a)
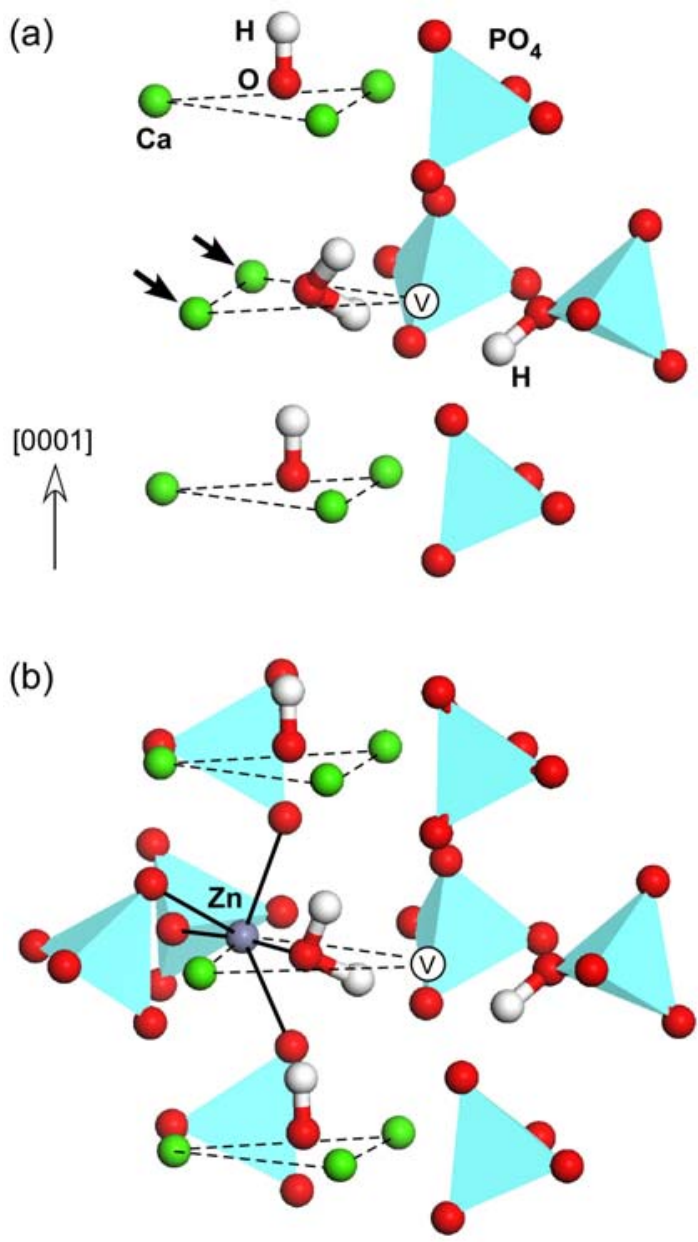

Fig. 1. Atomic structures of defect complexes in (a) pure HAp and (b) $\mathrm{Zn}^{2+}$-doped HAp. Ca atoms (green spheres) in the figures all correspond to triangular Ca-2 atoms about the $\mathrm{OH}$ arrangement along the $c$ axis. In (a), the $\mathrm{Ca}^{2+}$ vacancy at the Ca-2 site is charge-compensated by two protons [18], where the original position of Ca-2 removed to form the vacancy is depicted by ' $\mathrm{V}$ '. Two thick arrows in (a) indicate Ca-2 atoms replaced by $\mathrm{Zn}^{2+}$ to simulate $\mathrm{Zn}-\mathrm{K}$ XANES shown in Fig. 2. In (b), the optimized atomic structure of substitutional $\mathrm{Zn}^{2+}$ associated with the $\mathrm{Ca}^{2+}$-vacancy defect complex is displayed. 
(a)

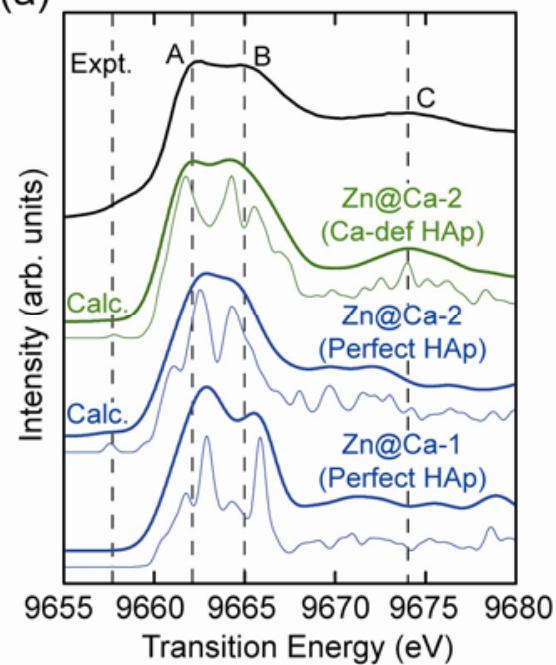

(b)

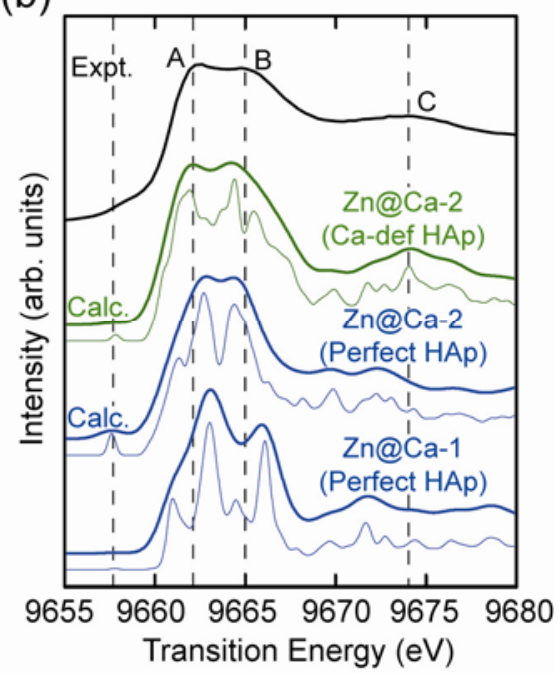

Fig. 2. Experimental $\mathrm{Zn}-\mathrm{K}$ XANES for $\mathrm{Zn}^{2+}$-doped HAp in comparison with theoretical ones. The computed spectra obtained by the pseudopotential method (CASTEP) were displayed in (a), while those by the APW+lo method (WIEN2k) in (b). The theoretical spectrum denoted as 'Ca-def HAp' in parentheses corresponds to substitutional $\mathrm{Zn}^{2+}$ associated the $\mathrm{Ca}^{2+}$-vacancy complex, whose atomic structure is depicted in Fig. 1(b). While the calculated spectra denoted as 'Perfect HAp' in parentheses indicate isolated substitutional $\mathrm{Zn}^{2+}$ at the Ca- 1 and Ca-2 sites of the perfect HAp lattice. The respective computed spectra were drawn by using FWHM of $0.5 \mathrm{eV}$ (thin lines) and $1.67 \mathrm{eV}$ (thick lines), in order to compare them with experiment or to highlight the detailed spectrum features. 


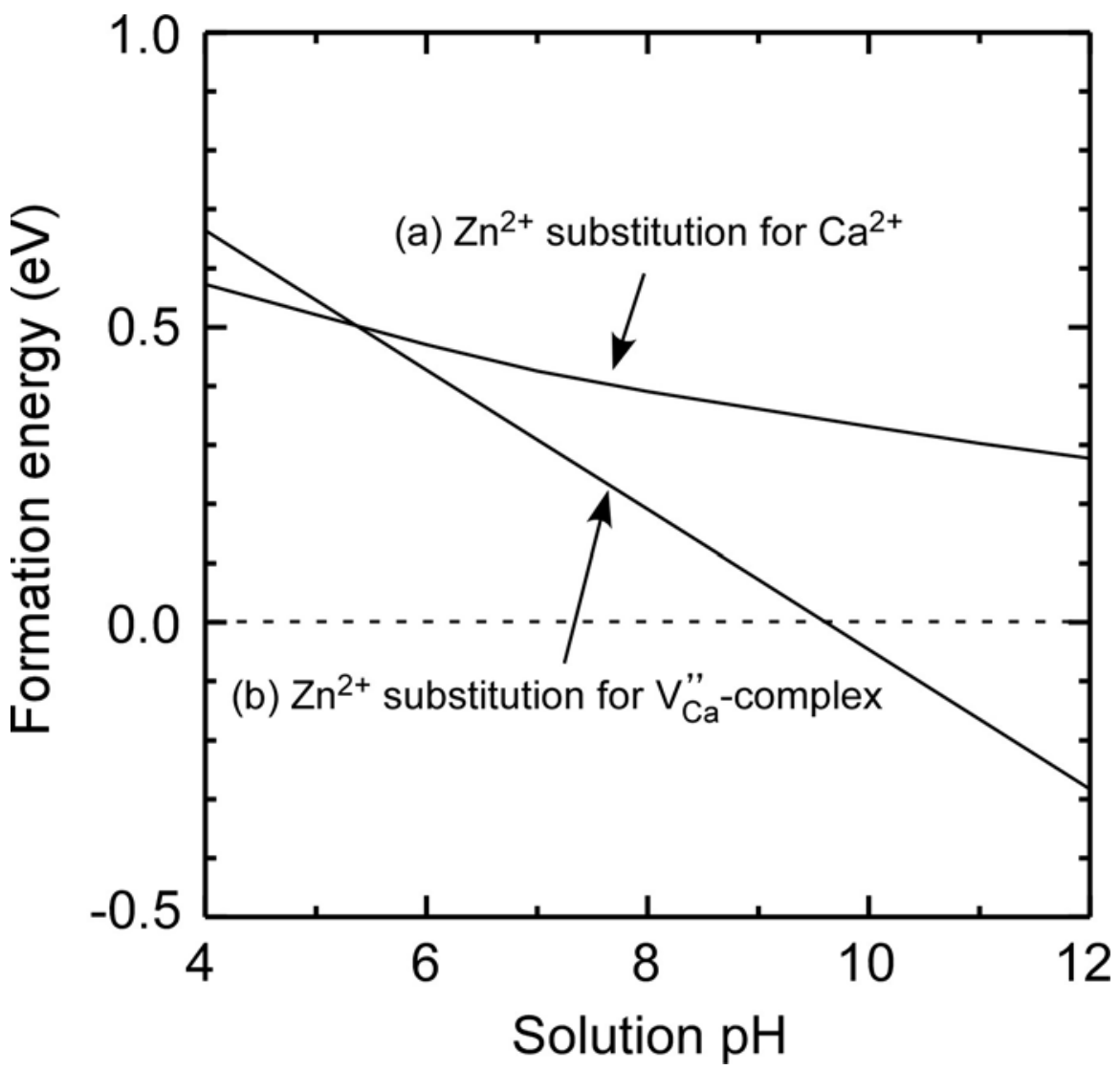

Fig. 3. Calculated formation energies of substitutional $\mathrm{Zn}^{2+}$ via different formation mechanisms, as a function of solution $\mathrm{pH}$. The mechanism (a) assumes that doped $\mathrm{Zn}^{2+}$ simply substitutes $\mathrm{Ca}^{2+}$ at $\mathrm{Ca}-2$ in perfect HAp. Then the formation energy tends to decrease with increasing $\mathrm{pH}$, and yet the energy over the $\mathrm{pH}$ range results in a negligible defect concentration [8]. The mechanism (b) corresponds to $\mathrm{Zn}^{2+}$ occupying the $\mathrm{Ca}^{2+}$-vacancy charge-compensated by two protons. By this mechanism, $\mathrm{Zn}^{2+}$ ions can be much more easily incorporated into HAp in more alkaline conditions. 